\title{
THE VERIFICATION OF AXIAL FORCES AND TORQUES IN DRILLING BY THE NONCOATED CUTTING TOOLS AND DRILLS WITH PVD TIN COATING
}

\author{
MAJERIK, J[ozef]; JAMRICHOVA, Z[uzana] \& DOBRIKOVA, M[iroslava]
}

\begin{abstract}
The main aim of this scientific paper is to assess the contribution of surface layers of bearing steel by determining the experimental measurement of cutting forces in the drilling technology with the drilling cutting tools made of uncoated high speed steel and also with coated by the PVD method. This experimental paper is a continuation of the solutions of grant VEGA no. 1/9428/02 titled "The technological heredity of the machined surfaces - surface integrity”. The first chapter of this scientific study discussed about the possibilities and technological challenges in drilling of bearing steels. The second chapter discusses about technological characteristics of cutting process and cutting forces. In the third and fourth chapter is described the measurement of cutting forces in drilling by the piezoelectric Kistler dynamometer. This paper, together with published results is a basis that will enable optimizing the quality of drilling production process, automotive parts of their dominant functional areas. The process of drilling was carried out in triaxial CNC milling machines with post iTNC530 HEIDENHAIN control systems. During drilling through dynamomatra were measured axial cutting forces and torques.
\end{abstract}

Keywords: cutting forces, drilling, PVD coatings, dynamometer KISTLER, HEIDENHAIN iTNC530

\section{INTRODUCTION}

The main aim of this experimental paper is to study and analyze the experimental measurement of the axial cutting forces and torques at drilling of specimen part made from bearing steel TYPE2 (STN 14 140). This measurement was successively analyzed and experimentally verified on selected sample material $45 \times 100 \times 300 \mathrm{~mm}$ outside the cut milling (for experimental measuring of the axial cutting forces and torques during the drilling process and measured and results designated with the piezoelectric KISTLER dynamometer (Fig.3).

Drilling technology is a part of the manufacturing process, which is based on the use of energy delivered by the machine tool, which is an activity (for the interaction with machinery and cutting tool) is formed workpiece (part) in the desired shape, dimensions and surface quality by taking a certain amount of cutting tool material [10].

Application materials for the cutting tools are defined by their physical, chemical, thermal and mechanical properties [6].
The term does not include only a machining process or a description of how to make machinery component removal of excess material, but also clarifying and explaining existing factors and phenomena in the machining process. Drilling is therefore also its scientific, not only practical part. Therefore, we are talking just about the theory of machining as well as experimental methods. The theory provides hypotheses that are experimentally verified and the verification of the hypothesis becomes a theory validation.

In theory aside the agreed convention for marking and cutting action of cutting forces, as well as forces that associated with an internal resistance of the cutting material [13].

One of the management strategies for business success in the market is a strategy of continuous improvement of production quality through the implementation of quality management and continuous improvement. Improving product quality then affects not only the production processes, but also post-production activities [7].

One of the main process engineering company is a manufacturing process that can be improved, including through implementation of new technologies and production processes in drilling to activities related to experimental measurements of axial cutting forces and torques in drilling technology.

Cutting force is tied to the relative movement between tool and workpiece. As relates to the resistance to motion, it cannot be regarded as a constant variable in time [2].

Research on cutting forces in machining of metals is not only practical but also theoretical importance. Theoretical knowledge of the cutting forces to refine theories about the cutting process. In practice, again knowledge of the importance of cutting forces for design tools, the selection of cutting conditions, calculations and design of machine tools etc. [12].

Links between technology and machining surface quality, building on their functionality in the future must cover the entire technological world, they show ways to deal with ever-increasing demands on product quality and offered use of reserves resulting [1]. 


\section{CNC DRILLING TECHNOLOGY}

Cutting properties of high-speed twist drills without coating, and also with wear resistant PVD coatings are mutually compared by measuring the mean values of axial (feed) $F_{f}$ cutting forces and torque Mc, impassable when drilling holes to a depth of $\mathrm{L}=3 \cdot \mathrm{D}$, using intensive cooling emulsion. Drilled test sample material was used on 14 dimensions $45 \times 100 \times 300140.3 \mathrm{~mm}$, with surface machining by milling technology. Mechanical properties of material are $\mathrm{R}_{\mathrm{m}}=895 \mathrm{MPa}, \mathrm{R}_{\mathrm{p} 0,2}=798 \mathrm{MPa}, \mathrm{A}_{05}=$ $15,2 \%, \mathrm{HV}_{5}=278[5,9]$.

In the process of experiments were used twist drills of high speed steel type HSSCo5=19 855, DIN 338, ø 6mm, without coating, and cross cut-sharpening drills type C, furthermore drills made of $\mathrm{z}$ high speed steel HSSCo5 = 19 855, DIN 338, ø 6mm, with surface treatment $-\mathrm{N}$, sharpening type $\mathrm{C}$ drilling tools made from high speed steel HSSCo5 $=19$ 855, DIN 338, ø 6mm, with PVD TiN coating, sharpening C, and then drills type DIN 338$\mathrm{N}$, sharpening the cutting edge of the transverse width $\breve{\mathrm{s}}_{\mathrm{p}}=1,3 \mathrm{~mm}$, cylindrical collar for circuit $\breve{\mathrm{s}}=0,8 \mathrm{~mm}$, with the same geometry, but made from HSSMo5= STN 19830

Experimental drilling and measurement was realized on vertical $\mathrm{CNC}$ machine tool $\mathrm{FV} 25 \mathrm{~A} \mathrm{CNC}$ with $\mathrm{P}=15$ $\mathrm{kW}$ performance, and with HEIDENHAIN iTNC530 control system (Fig. 1). Speed range of the machine is $\mathrm{n}_{\max }=6000 \mathrm{~min}^{-1}$, range of feed rates $\mathrm{v}_{\mathrm{f}}=1 \div 2000 \mathrm{~m} \cdot \mathrm{min}^{-1}$, rapid traverse $\mathrm{v}_{\mathrm{f}}=6000 \mathrm{~mm} \cdot \mathrm{min}^{-1}$. How cool was used semi-synthetic coolant emulsion CIMSTAR 560 5\%, with amount $\mathrm{Q}=10 \div 30 \mathrm{dm}^{3} \cdot \mathrm{min}^{-1}\left(\mathrm{~L} \cdot \mathrm{min}^{-1}\right)$, with external supply. Recommended cutting conditions for drilling workpiece material were as follows. Cuting speeds $\mathrm{v}_{\mathrm{c}}=13,4-16,9-21,1-33,9 \mathrm{~m} \cdot \mathrm{min}^{-1}$. Frequency of rotation $: \mathrm{n}=710-900-1120-1800 \mathrm{~min}^{-1}$. Feeds $\mathrm{f}=$ $0,03-0,05-0,08-0,12 \mathrm{~mm}$. Feed rate $\mathrm{v}_{\mathrm{f}}=33,6$ až $134,4 \mathrm{~mm} \cdot \mathrm{min}^{-1}$.

The direct capture components of cutting forces are most frequently used piezoelectric dynamometer. It is possible to measure one, two, or three components of cutting force or torque [3].

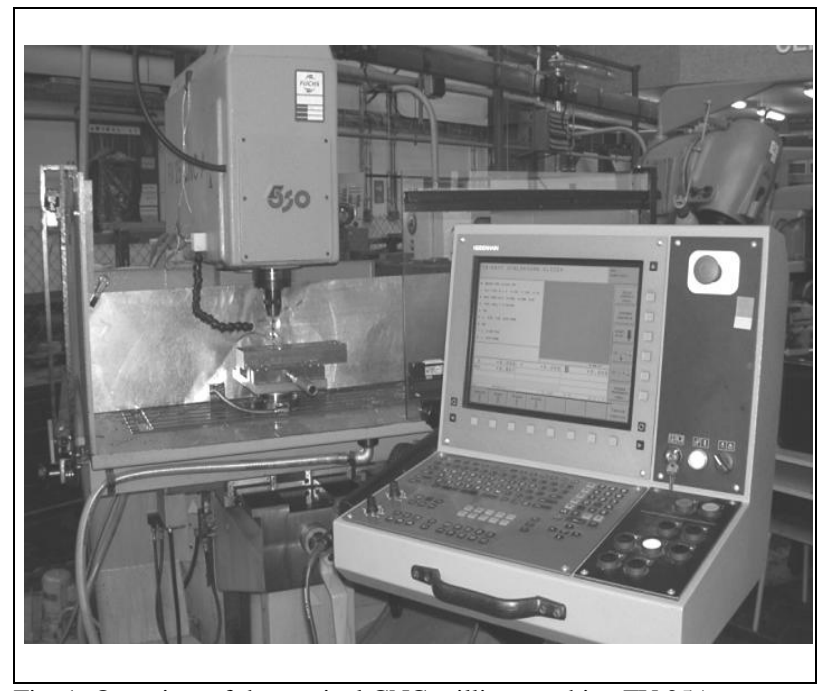

Fig. 1. Overview of the vertical CNC milling machine FV 25A

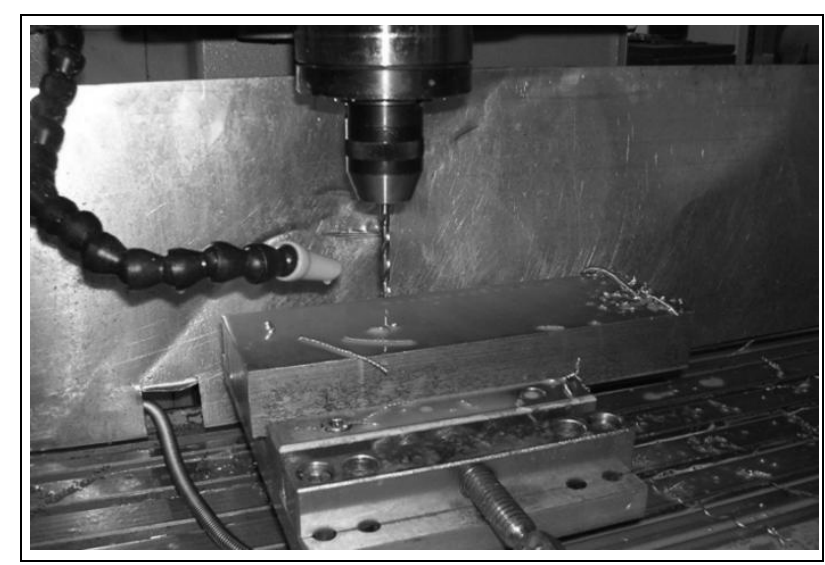

Fig. 2. Piezoelectric dynamometer KISTLER 9272 B

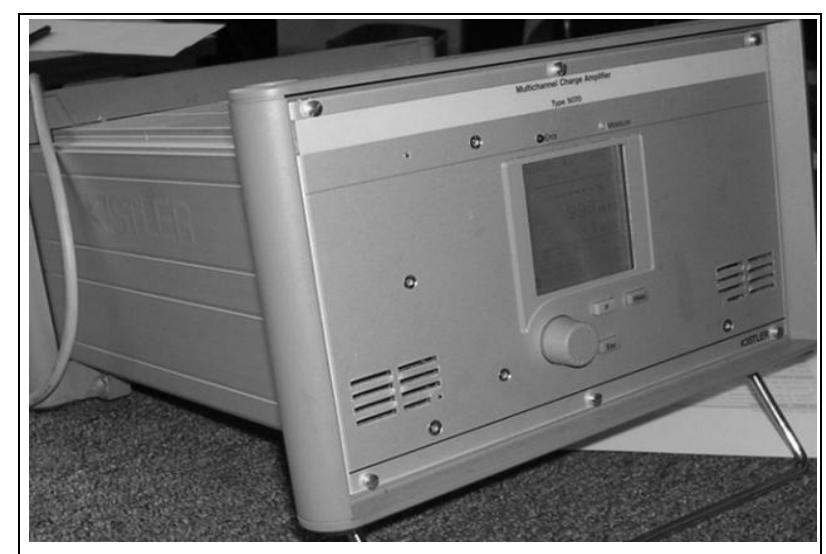

Fig. 3. Device for measuring the axial cutting force $\left(\mathrm{F}_{\mathrm{f}}[\mathrm{N}]\right)$ and torque $\left(\mathrm{M}_{\mathrm{c}}[\mathrm{Nm}]\right)$. An overview of quaternary piezoelectric dynamometer KISTLER 9272 B completely computer controlled, a charge amplifier type KISTLER 5011 A

\section{EXPERIMENTAL MEASUREMENT}

The main aim was to determine the load measuring drill of $\varnothing 6 \mathrm{~mm}$ and drilling process analysis using mathematical-physical models on computer. Experiments measuring $F_{f}$ and $M_{c}$ builds on previous drilling conducted experiments in determining the durability of drills followed HSSCo5 (O-N-TiN) at different cutting speeds but constant feed $\mathrm{f}=0.08 \mathrm{~mm}$ and cooling $\mathrm{E} 5 \%$ $\left(\mathrm{Q}=1.0 \mathrm{dm}^{3} \cdot \mathrm{min}^{-1}\right)$ to the FV25 CNC machine (Fig. 2).

\subsection{Experiment I}

During the tests, we drilled of $\varnothing 6$ × $21 \mathrm{~mm}$ holes into the material steel type 14140.3 was first being aware of the dependence $F_{f}=f(f)$, and $M_{c}=f(f)$ at constant cutting speed $\mathrm{v}_{\mathrm{c}}=21.1 \mathrm{~m} \cdot \mathrm{min}^{-1}$, ie with $\mathrm{n}=1120 \mathrm{~min}^{-1}$, using a cooling and a change following feeds: $f=0.03$ to $0.05-0.08$ to $0.12 \mathrm{~mm}$. Mean values of measured axial forces $F_{f}[N]$ when drilling $\varnothing 6 \times 21 \mathrm{~mm}$ holes into the material 14140.3 (TYPE2), for different values of the shifts, which are listed in Table1. Mean values $\mathbf{M}_{\mathrm{c}}$ torque [Nm] drilling Ø6 x $21 \mathrm{~mm}$ with cooling in 14140.3 steel material, with different feeds are shown in Table 2.

\begin{tabular}{|c|c|c|c|c|}
\hline \multirow{2}{*}{$\begin{array}{c}\text { Drill } \\
\text { Feed f [mm] }\end{array}$} & \multicolumn{4}{|c|}{ Drilling with coolant CIMSTAR 560- E5 \% } \\
\cline { 2 - 5 } & $O_{10}-H S S 55$ & $N_{10}$ & TiN $_{7}$ & HSS 30 \\
\hline 0,03 & 206 & 304 & 171 & 435 \\
\hline 0,05 & 324 & 439 & 242 & 570 \\
\hline 0,08 & 484 & 591 & 351 & 750 \\
\hline 0,12 & 707 & 778 & 466 & 1011 \\
\hline
\end{tabular}

Tab. 1. Mean values of axial cutting forces $F_{f}[N]$ at drilling, at various values of feed motions 


\begin{tabular}{|c|c|c|c|c|}
\hline \multirow{2}{*}{$\begin{array}{c}\text { Drill } \\
\text { Feed f } \\
{[\mathrm{mm}]}\end{array}$} & \multicolumn{4}{|c|}{ Drilling with coolant CIMSTAR 560 -E5 \% } \\
\cline { 2 - 5 } & $O_{10}-H S S 55$ & $N_{I 0}$ & $\mathrm{TiN}_{7}$ & HSS 30 \\
\hline 0,03 & 0,70 & 0,80 & 0,60 & 0,75 \\
\hline 0,05 & 0,86 & 0,95 & 0,82 & 0,92 \\
\hline 0,08 & 1,30 & 1,41 & 1,17 & 1,42 \\
\hline 0,12 & 1,86 & 2,04 & 1,62 & 2,00 \\
\hline
\end{tabular}

Tab. 2. Mean values of torques $\mathbf{M}_{\mathrm{c}}[\mathrm{Nm}]$ at drilling, at various values of feed motions

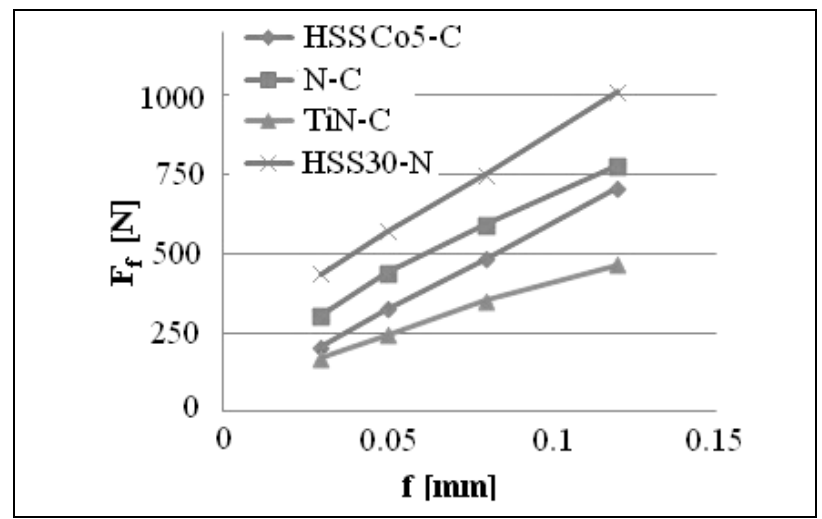

Fig. 4. Course of axial force $F_{f}$ for drill ø $6 \mathrm{~mm}$ at various feeds

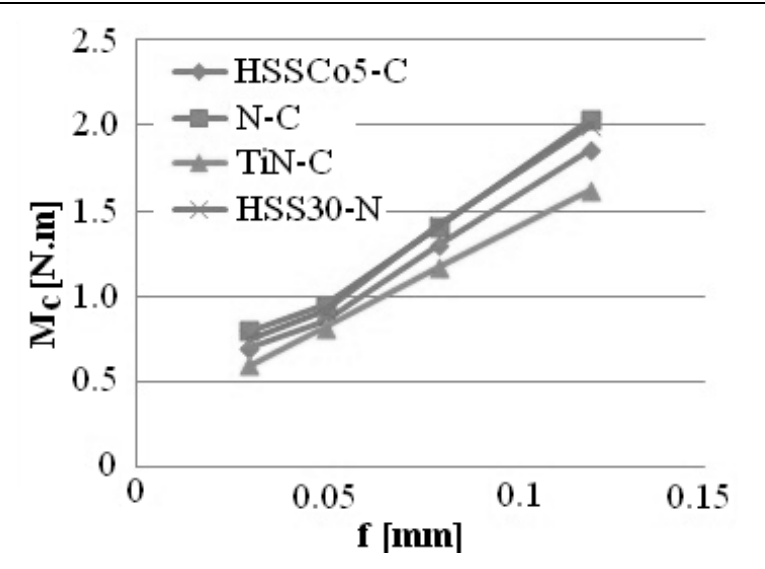

Fig. 5. Course of torque $\mathrm{M}_{\mathrm{c}}$ for drill ø $6 \mathrm{~mm}$ at various feeds

A comparison of uncoated HSS drilling cutting tools HSSCo5 and HSSCo30 is based on the HSS $30=19830$ $\mathrm{N}$ sharpening with increasing axial forces caused by 43 to $100 \%$ and increase torque by $7 \div 9 \%$. Nitrided drills exhibited in this case, durability is very low, and after only four holes were drilled wear $\mathrm{VB}_{\max }=0.4 \div 0.6 \mathrm{~mm}$. The course of the axial (feed) forces $\mathrm{F}_{\mathrm{f}}$ and torque to drill $\varnothing 6 \mathrm{~mm} \times 21 \mathrm{~mm}$ holes with uncoated (O), ion nitriding (N) and PVD TiN coating cutting tools in different feeds is shown in Figure 4 and also in Figure 5.

\subsection{Experiment II}

Measuring of axial cutting forces $F_{f}[N]$ and $M_{c}$ torque $[\mathrm{Nm}]$ at a constant feed motion rate $\mathrm{f}=0.08 \mathrm{~mm}$, that the normative recommended cutting conditions for drilling were $\varnothing 6 \mathrm{~mm}$, but at different cutting speeds in the range: $\mathrm{v}_{\mathrm{c}}=13.4$ to $16,9-21.1$ to $33.9 \mathrm{~m} \cdot \mathrm{min}^{-1}(\mathrm{n}=$ $710-900-1120$ to $1800 \mathrm{~min}^{-1}$ ). Mean values of measured axial cutting forces $F_{f}$ and torques $M_{c}$ drilling $\varnothing 6 \times 21 \mathrm{~mm}$ of 14140.3 material at a constant feed motion rate $\mathrm{f}=0.08 \mathrm{~mm}$ and changing the cutting speed, using cooling for various coated and uncoated drilling cutting tools are listed in Table 3 and table 4 . While changing the torque $\mathrm{M}_{\mathrm{c}}[\mathrm{Nm}]$ drilling $\varnothing 6 \times 21 \mathrm{~mm}$ of 14
140.3 material at a constant feed rate $\mathrm{f}=0.08 \mathrm{~mm}$ and changing the cutting speed are monitored for drills presented in Fig. 6 and 7. Experiment conditions: $f=$ $0,08 \mathrm{~mm}=$ const., ${ }_{\mathrm{f} 1}=56,8 \mathrm{~mm} \cdot \mathrm{min}^{-1}$ at $\mathrm{n}_{1}=710 \mathrm{~min}^{-1}$, $\mathrm{v}_{\mathrm{f} 2}=72 \mathrm{~mm} \cdot \mathrm{min}^{-1}$ at $\mathrm{n}_{2}=900 \mathrm{~min}^{-1}, \mathrm{v}_{\mathrm{f} 3}=89,6 \mathrm{~mm} \cdot \mathrm{min}^{-1}$ at $\mathrm{n}_{3}=1120 \mathrm{~min}^{-1}, \mathrm{v}_{\mathrm{f} 4}=144 \mathrm{~mm} \cdot \mathrm{min}^{-1}$ at $\mathrm{n}_{4}=1800 \mathrm{~min}^{-}$ 1 .

\begin{tabular}{|c|c|c|c|c|}
\hline \multirow{2}{*}{$\begin{array}{c}\text { Drill } \\
\mathrm{v}_{\mathrm{c}}\left[\mathrm{m} \cdot \mathrm{min}^{-1}\right]\end{array}$} & \multicolumn{4}{|c|}{ Drilling with coolant CIMSTAR 560-E5 \% } \\
\cline { 2 - 5 } & $O_{10}-H S S 55$ & $N_{l l}$ & $T i N_{7}$ & $H S S 30$ \\
\hline 13,38 & 454 & 469 & 390 & 867 \\
\hline 16,9 & 452 & 463 & 381 & 824 \\
\hline 21,1 & 450 & 462 & 368 & 782 \\
\hline 33,9 & 447 & 458 & 343 & 763 \\
\hline
\end{tabular}

Tab. 3. Mean values of axial cutting forces $F_{f}[N]$ at drilling

\begin{tabular}{|c|c|c|c|c|}
\hline \multirow{2}{*}{$\begin{array}{c}\text { Drill } \\
\mathrm{v}_{\mathrm{c}}\left[\mathrm{m} \cdot \mathrm{min}^{-1}\right]\end{array}$} & \multicolumn{4}{|c|}{ Drilling with coolant CIMSTAR 560-E5\% } \\
\cline { 2 - 5 } & $O_{10}-$ HSS 55 & $N_{I 1}$ & TiN & HSS 30 \\
\hline 13,38 & 1,60 & 1,53 & 1,48 & 1,63 \\
\hline 16,9 & 1,43 & 1,37 & 1,40 & 1,44 \\
\hline 21,1 & 1,31 & 1,22 & 1,20 & 1,35 \\
\hline 33,9 & 1,12 & 1,18 & 1,11 & 1,16 \\
\hline
\end{tabular}

Tab. 4. Mean values of torques $\mathrm{M}_{\mathrm{c}}[\mathrm{Nm}]$ at drilling

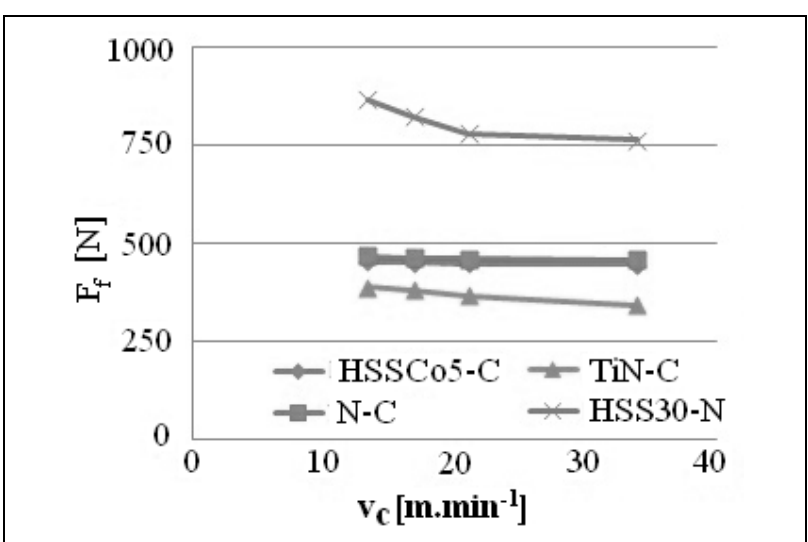

Fig. 6. Course of axial force $\mathrm{F}_{\mathrm{f}}$ for drill $\varnothing 6 \mathrm{~mm}$ at various feeds

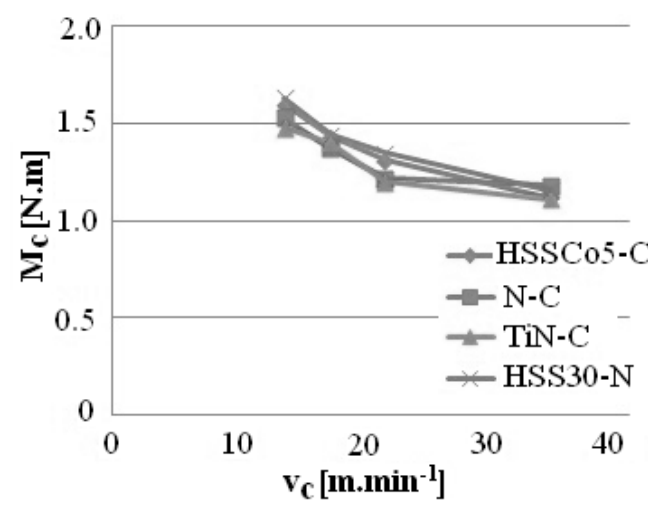

Fig. 7. Course of torque $\mathrm{M}_{\mathrm{c}}$ for drill $ø 6 \mathrm{~mm}$ at various feeds

\section{THE EVALUATION OF RESULTS}

As is shown in a graph of average values $F_{f}$ and $M_{c}$ according to the feed rate, at $\mathrm{v}_{\mathrm{c}}=21.1 \mathrm{~m} \cdot \mathrm{min}^{-1}$ (Table 1 and 2), this dependence of linear regression process, e.g. both increase with increasing shift (Fig. 4, 5), and fall (Fig. 6, 7). The coated drill cutting part, in accordance with the dependence $T=f\left(v_{c}\right)$, Ff sizes are larger than uncoated drill HSSCo5, due to more wear and tear to the cutting edge delamination after only 4 holes drilled. 


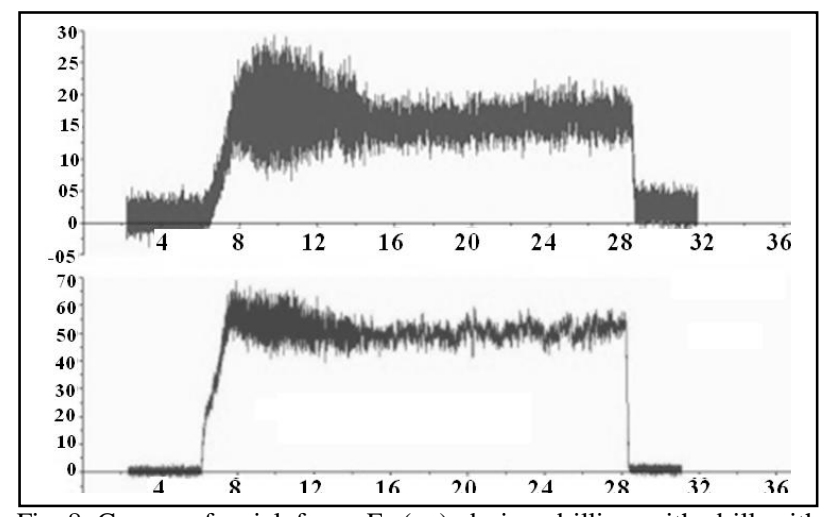

Fig. 8. Course of axial force $\mathrm{F}_{\mathrm{f}}$ (up) during drilling with drill with sharpening type $\mathrm{C}$ (horizontal axis - time, vertical $\mathrm{F}_{\mathrm{f}}$ and $\mathrm{M}_{\mathrm{c}}$ )[5]

The smallest $\mathrm{F}_{\mathrm{f}}$ and $\mathrm{M}_{\mathrm{c}}$ were measured with PVD TiN coated drills, with minimal wear after 4 to 8 drilled holes. The greatest value of the axial force $F_{f}$ and $M_{c}$ were measured during drilling with uncoated drill HSSMo5 = 19830 with $\mathrm{N}$-shaped sharpening, ie the transverse width of the cutting edge $\mathrm{s}_{\mathrm{p}}=1.3 \mathrm{~mm}$. At cross cutting edge increases the axial forces more than $43 \%$ to $76 \%$ over uncoated drill with a $\mathrm{C}$-shaped cross multiple section and $\mathrm{M}_{\mathrm{c}}$ increase of $7 \div 9 \%$. Dependences of $\mathrm{F}_{\mathrm{f}} \mathrm{M}_{\mathrm{c}}$ with drill bit sharpening $\mathrm{C}$ is shown in Fig. 8. The difference is in the variation of axial force and torque at the beginning of collaring the bit into the material at the start of drilling. At the beginning of drilling (collaring the bit) with $\mathrm{N}$ sharpening, there is a greater increase in vibration and dynamic axial force $F_{f}$ and especially torque $M_{c}$ compared with drill sharpening $\mathrm{C}$. Even in experiments II, when changing $F_{f}$ and $M_{c}$ subject to change cutting speed $\left(v_{c}\right)$ at a constant feed rate $f=0.08 \mathrm{~mm}$ shows that the smallest value of $F_{f}$ and $M_{c}$ are in PVD TiN coated drill and the largest drill in uncoated HSSMo5 = 19830 , with sharpening $\mathrm{N}$ (transverse width of cutting edge $\mathrm{s}_{\mathrm{p}}=$ $1.3 \mathrm{~mm}$ compared to $0.3 \mathrm{~mm}$ in cross-sharpening $\mathrm{C}$ ). Proper writing methodology was created, which would be able to define the communication ways between single devices during machining process [4].

The total cutting force induced by the action of the cutting tool to the workpiece is called the symbol F. For the analysis of power relationships cutting process, the resulting cutting force $F$ breaks down into relevant components. During the act of machining the workpiece cutting force $\mathrm{F}$, which is the vector can be separated into individual components [11].

\section{CONCLUSION}

Practical experiments of the measurement of axial cutting forces $F_{f}$ and torques $M_{c}$ confirmed,the fact, that the surface of coated drills to test our worn down to $\mathrm{VB}_{\max }=0.6 \mathrm{~mm}$ after drilled of 4 holes while the tool coated with TiN was finish after 8 holes with no measurable wear on surface of cutting tool.

The practical benefit is the finding that in bearing steels machinability is attained by $\mathrm{R}_{\mathrm{a}}$ good and improves with increasing the hardness (strength). Effect of cutting speed of change of tangential cutting force $F_{c}$ was not measured. That opens the way for further research in this area, to optimize the process of $\mathrm{CNC}$ drilling machine parts from bearing steels in the production of their dominant functional areas.
On the basis of experience, we can state that the system of quality management processes is beneficial only if it is constantly improving. It is necessary to improve all activities and anything that can improve a company based on the constantly changing needs of the real experience and customer demand that is continuously gathering customer feedback and satisfaction regarding their views on the process improvement [7].

Timely communication with customers and experience we can ensure a smooth launch of new standards, as the arrival of new technologies and systems with you and automatically gives them a very positive change [8].

\section{ACKNOWLEDGEMENTS}

Our presented technical scientific paper is link between the drilling theory and industrial practice. The practical measurement of specimen part was conducted in collaboration with the Faculty of Mechanical Engineering Brno University of Technology, along with industrial companies of the region Trencin (e.g. Co. Technodat CAE Systems Trencin). It also builds on the project VEGA 1/9428/02, which was successfully resolved at the Alexander Dubcek University of Trencin at Faculty of Special Technology in Trencin.

\section{REFERENCES}

[1] Batora, B.; Vasilko, K. (2000). Machined surfaces, technological heredity, functionality, FST TnU, ISBN 80-88914-19-1, Trencin, Slovakia

[2] Beno, J. (1999). Theory of cutting metals, SjF TUKE, ISBN 807099-429-0, Kosice, Slovakia

[3] Beno, J.; Mankova, I. (2004). Technological and material factors of machining, SjF TUKE, ISBN 80-7099-701-X, Kosice, Slovakia

[4] Danisova, N.; Sebenova, S. \& Velisek, K. (2011). Application of seguence diagram within tool change during machining, Annals of DAAAM for 2011\&Proceedings of the 22nd International World Symposium, 23-26th November 2011, Austria center Vienna, ISSN 1726-9679, ISBN 978-3-901509-70-4, Katalinic, B. (Ed.), pp. 0459-0460, TUV, Vienna, Austria

[5] Dobrikova, M. (2012). Influence of surface treatment on the wear resistance drilling tools, Ph.D. Dissertation, Department of maintenance technology, FST TnUAD, Trencin, Slovakia

[6] Humar, A. (2008). Materials for cutting tools, MM Publishing, ISBN 978-80-254-2250-2, Prague, Czech republic

[7] Jambor, J. (2010). Analysis of the results of audits of quality management system - sales service of cars, Quality Innovation Prosperity, Vol.14, No. 1-2, ISSN 1335-1745, p.1-8, Slovakia

[8] Lechan, P.; Jambor, J. (2007). SEAT Service quality management system, International scientific conference of Vehicles, SPU, ISBN 978-80-8069-942-0, Nitra 2007, Slovakia, p. 119-123

[9] Jamrichova, Z. (2001). Computer support of manufacturing process, November 2001,Transfer 2001, ISBN 80-88914-46-9, pp. 387-389, FST TnU, Trencin, Slovakia

[10] Majerik, J.; Sandora, J. (2012). The new progressive cutting tools and machining technology methods, FST TnUAD, ISBN 978-808075-515-7, Trencin, Slovakia

[11] Neslusan, M.; et al. (2007). Experimental methods in machining, SjF ZU, ISBN 978-80-8070-711-8, Zilina, Slovakia

[12] Piska, M.; Forejt, M. (2006). Theory of machining and cutting tools, UST FSI VUT, ISBN 80-214-2374-9, Brno, Czech republic

[13] Vasilko, K. et al. (2006). Top trends in machining, technology of machining- part III., Mediast, ISBN 80-968954-2-7, Zilina, Slovakia 